\title{
Potential for Alkali-Silica Reaction in Radiation Shielding Concrete Containing Special Aggregates
}

\author{
Daria Jóźwiak-Niedźwiedzka, Michał A. Glinicki, and Karolina Gibas \\ Institute of Fundamental Technological Research Polish Academy of Science, \\ Pawińskiego 5B, 02-106, Warsaw, Poland
}

\begin{abstract}
In the present study, the potential for the alkali-silica reaction (ASR) in radiation shielding concrete containing special aggregates is presented. The tests were performed on two kinds of aggregate: (1) high-density aggregate to absorb the gamma radiation (barite, magnetite, and hematite) and (2) mineral with high bound water content to attenuate the neutron flux (serpentinite). The optical microscopy in transparent light on thin sections, XRD and XRF method, was used to assess the mineral composition of aggregates. ASTM C1260 test method for potential alkali reactivity of aggregates was applied also to investigate the effect of different content and crystal size of silica on the expansion due to ASR. The tests revealed that all tested aggregates, such as barite, magnetite, hematite, and serpentinite, were characterized by low solubility at high $\mathrm{pH}$. The XRD and XRF results have shown presence of silica in all tested aggregates, but the microscopic observations enhanced size and composition of $\mathrm{SiO}_{2}$ crystals. The aggregates were not deleterious themselves, but the different content and size of $\mathrm{SiO}_{2}$ crystals in the aggregate influenced their potential for alkali-silica reaction. The quartz in heavy kinds of rocks and in the serpentinite used for radiation shielding was just as much potentially susceptible to deleterious ASR as quartz in common rocks used in concrete technology. In the hematite, silica crystals were classified as microcrystalline, so it should be considered as potentially reactive. The expansion tests confirmed that hematite was highly reactive. Other aggregates after 14 days of testing did not exceed $0.1 \%$ elongation limit. The microstructural analysis of thin sections prepared from mortars after ASTM C1260 test confirmed expansion of aggregate grains due to ASR.
\end{abstract}

\section{INTRODUCTION}

Nuclear shields and containments are designed to withstand loads from over-pressure in the reactor building in the event of a severe accident such as core damage. While not enduring the design-accident pressure loads, shields and containments are subject to operating loads and other stressors [such as environmental loads, concrete aging, material deterioration like the aggregates' alkali-silica reaction (ASR), etc.] which erode their capacities, reduce their reliability, and increase their failure rate with time (Saliba et al., 2010; Vonloh, 1981). It is known that the high-density aggregate and aggregates containing water that are used in shielding concrete present special problems. High-density aggregates are used to absorb gamma rays, and light atomic weight aggregates are used to attenuate neutrons. Some of the special aggregates may contain clays and are also likely to be friable, so that it may be expected to produce considerable amounts of fines during concrete mixing. Either situation will raise the amount of water needed for required workability or the consequences will include more segregation and bleeding of concrete, lower strength, and increased tendency to crack (Mather, 1965).
In unreinforced concrete, ASR results in pattern cracking while in reinforced concrete long cracks parallel to the direction of longitudinal reinforcement are observed with random thin cracks bridging the longitudinal cracks (Swamy, 1992). Although it occurred that collapse of the concrete structure was due to an alkali-silica reaction. Such a phenomenon may significantly affect permeability and therefore durability of the concrete structure.

The most common natural aggregates used in radiation-shielding concrete (RSC) are produced from ores of high-density minerals, such as barite, hematite, magnetite, and ilmenite. Other aggregates used in RSC include aggregates that contain bound water, produced from ores of hydrous iron, serpentine, or bauxite (Lee, Daugherty, \& Broton, 2013), and aggregates that contain boron, produced from natural borate ores - ulexite or colemanite.

Few studies have focused on the radiation influence on the properties of the special aggregates. Ichikawa and Koizumi (2002) and Pomaro, Salomoni, Gramegna, Prete, and Majorana (2010) indicated that radiation damage in concrete aggregates was caused by changes in the lattice structure of minerals in the 
aggregates. Nuclear radiation significantly increased the reactivity of silica-rich aggregates to alkalis in concrete. Crystalline quartz, or $\alpha$-quartz with specific gravity of about 2.65 , due to irradiation was converted to distorted amorphous quartz with specific gravity of 2.27. Ichikawa and Koizumi (2002) stated that silicarich aggregates in irradiated concrete are prone to react with alkali even the aggregates were carefully selected to be innocuous to the alkali-silica reaction.

However, the tests for possibility of alkali-silica reaction before radiation of the special aggregate were not executed. Recent observations of premature deterioration of nuclear shielding concrete structures in Seabrook Power Plant (US, NH) have suggested the development of the ASR. Expansion produced by alkali-silica reaction has been also observed in lkata nuclear power station (NPP) in Japan, in Gentilly in Canada, and in Saint-Laurent in Saint-Laurent, France. The concrete degradation due to ASR on the external face of the containment building of Tihange 2 in Belgium has been observed also (Jóźwiak-Niedźwiedzka et al., 2015). These examples demonstrate that the issue of ASR was not considered seriously during the material selection for NPP structures.

The reactive minerals in aggregate may be present in a small amount and their distribution may vary among aggregates. Damage can be caused by as little as $0.5 \%$ of defective aggregate. So, it is important to prove that special aggregate which is used for concrete in nuclear power structures is not prone to ASR, without any type of radiation (Jóźwiak-Niedźwiedzka et al., 2015).

The subject of this paper is the investigation of the possible alkali-silica expansion of special aggregates for nuclear shields. Tests were focused on both, heavy aggregates and aggregate with high content of bound water for nuclear shielding concrete.

\section{MATERIALS AND LABORATORY TEST METHODS}

\subsection{Materials}

Due to the special demands according to the aggregate for nuclear shielding concrete, two groups of aggregate have been tested: high-density aggregate (barite, magnetite, and hematite) and with high fixed water content (serpentinite). The aggregates tested in this study were acquired from four different quarries. Barite aggregate was imported from mines localized in Europe. Magnetite was also collected from an European mine, and hematite was from Africa. Serpentine was collected from mines located in Poland. Table 1 shows the main components of aggregates after XRF analysis. The densities were barite $4.2 \mathrm{~g} /$ $\mathrm{cm}^{3}$, magnetite $4.8 \mathrm{~g} / \mathrm{cm}^{3}$, and hematite $5.1 \mathrm{~g} / \mathrm{cm}^{3}$. High density makes them useful for heavyweight concrete, allowing for a required high density of concretes, as it is specified in shielding elements. The density of the serpentinite was $2.7 \mathrm{~g} / \mathrm{cm}^{3}$, but due to the content of chemical bonded water $(12 \%)$ it makes this aggregate adequate for the absorption of the flux of neutrons.

Table 1. Main components of tested aggregates after XRF method in \%, supplier's data.

\begin{tabular}{ccccc}
\hline $\begin{array}{c}\text { Main mineral } \\
\text { const. }\end{array}$ & Barite & Magnetite & Hematite & Serpentinite \\
\hline $\mathrm{BaSO}_{4}$ & 92 & $\mathrm{~N} / \mathrm{A}$ & $\mathrm{N} / \mathrm{A}$ & $\mathrm{N} / \mathrm{A}$ \\
$\mathrm{CaF}_{2}$ & 3.0 & $\mathrm{~N} / \mathrm{A}$ & $\mathrm{N} / \mathrm{A}$ & $\mathrm{N} / \mathrm{A}$ \\
$\mathrm{SiO}_{2}$ & 3.0 & 3.0 & 11.5 & 39.5 \\
$\mathrm{Fe}_{2} \mathrm{O}_{3}$ & $\mathrm{~N} / \mathrm{A}$ & 90.8 & 85.1 & 8.4 \\
$\mathrm{FeCO}_{3}$ & $\mathrm{~N} / \mathrm{A}$ & $\mathrm{N} / \mathrm{A}$ & $\mathrm{N} / \mathrm{A}$ & $\mathrm{N} / \mathrm{A}$ \\
$\mathrm{MgO}$ & $\mathrm{N} / \mathrm{A}$ & $\mathrm{N} / \mathrm{A}$ & 0.07 & 36.7 \\
$\mathrm{Al}_{2} \mathrm{O}_{3}$ & $\mathrm{~N} / \mathrm{A}$ & 0.4 & 0.9 & 0.9 \\
$\mathrm{CaO}$ & $\mathrm{N} / \mathrm{A}$ & 2.5 & 0.05 & 0.7 \\
$\mathrm{~K}_{2} \mathrm{O}$ & $\mathrm{N} / \mathrm{A}$ & 0.2 & 0.4 & 0.03 \\
$\mathrm{Na}_{2} \mathrm{O}$ & $\mathrm{N} / \mathrm{A}$ & 0.3 & 0.02 & 0.1 \\
\hline
\end{tabular}

Aggregates were also characterized using X-ray diffraction to identify their constitutive minerals. The detailed results are described in JóźwiakNiedźwiedzka, Brandt, Gibas, and Denis (2014). The mineral composition of aggregate called barite was barite - quartz, and fluorite; magnetite aggregate magnetite, cordierite, and fluorapatite; hematite aggregate - hematite and quartz; and serpentinite aggregate - chrysotile, antigorite, and lizardite. All XRD analyses confirmed the mineral composition of tested aggregate obtained from the suppliers, the XRF analysis has been used to verify the suppliers' data and the obtained results confirmed the chemical composition of the heavy aggregates (JóźwiakNiedźwiedzka et al., 2015).

The ordinary Portland cement CEM I 42.5R was used in the tests. The content of total alkalis, $\mathrm{Na}_{2} \mathrm{O}_{\text {eq }}$, was equal to $0.78 \%$, and water soluble alkalis $-0.54 \%$ by XRF method.

\subsection{Testing methods}

2.2.1 ASTM C1260 expansion test

ASTM C1260 Standard Test Method (Mortar-Bar method) method has been used to detect the potential for deleterious alkali-silica reaction of aggregate in mortar bar exposed to $\mathrm{NaOH}$ solution in $80^{\circ} \mathrm{C}$. Mortar bar specimens $25 \mathrm{~mm} \times 25 \mathrm{~mm} \times 285 \mathrm{~mm}$ were prepared, the aggregate was crushed and sieved according to the standard requirements. Aggregateto-cement ratio of 2.15 and water-to-cement ratio (by weight) of 0.47 were maintained. Three mortar bars were prepared for each aggregate type. The mortars 
were mixed and molded within a total elapsed time of $<2$ min and $15 \mathrm{~s}$. The mortar bars were kept in $23 \pm 2^{\circ} \mathrm{C}$ and $\mathrm{RH} \geq 95 \%$, for $24 \mathrm{~h}$. After $24 \mathrm{~h}$ in mould, the mortar bars were stored for the next $24 \mathrm{~h}$ in water in $80\left( \pm 1\left(^{\circ} \mathrm{C}\right.\right.$. Then, their initial zero readings were recorded by a digital extensometer before immersing in $1 \mathrm{~N} \mathrm{NaOH}$ at $80\left({ }^{\circ} \mathrm{C}\right.$ for 14 days, (Jóźwiak-Niedźwiedzka et al., 2015). Subsequent expansion readings were measured at least three times during the test. The final assessment of the potential reactivity of the tested aggregates was carried out on the basis mortar bar expansion (Table 2).

Table. 2. Assessment of reactivity of aggregate per ASTM C1260 (2014).

\begin{tabular}{cl}
\hline Expansion (\%) & Aggregate reactivity \\
\hline$<0.1$ & Innocuous \\
$0.1 \div 0.2$ & Inconclusive \\
$>0.2$ & Potentially deleterious \\
\hline
\end{tabular}

\subsubsection{Thin section analysis}

The fluorescent epoxy impregnated thin sections used for this study were prepared from both aggregate before Mortar-Bar Test only and mortars after 14 days of storing in $1 \mathrm{~N} \mathrm{NaOH}$ at $80^{\circ} \mathrm{C}$. The mortar specimens were cut in small blocks measuring $40 \mathrm{~mm} \times 50 \mathrm{~mm}$. The aggregate particles and the mortar blocks were vacuum impregnated using a low viscous yellow fluorescent. After hardening, one face of the block was ground using grinding equipment, which ensured plane parallel grinding throughout the process. After grinding, the specimens were impregnated a second time, in order to ensure proper impregnation of the capillary porosity. After hardening, the excess epoxy and part of the concrete beneath the impregnation surface were removed by grinding. An object glass was then glued onto the fully impregnated aggregate or mortar and the specimen cut in such a way that about $1 \mathrm{~mm}$ of the impregnated specimen was left on the glass. The aggregate or mortar slice was ground to thickness of 20-25 $\mu \mathrm{m}$. The thickness was controlled manually by watching the birefringence change of quartz in crossed polarized light. As the last step, a cover glass was glued onto the section prior to analysis (Jóźwiak-Niedźwiedzka, Glinicki, \& Dąbrowski, 2011).

Thin section analyses were carried on using the optical polarizing microscope Olympus BX51 connected to a digital camera. Thin sections were examined in plane polarized light (PPL), crossed polarized light (XPL), also with lambda plate and in UV light. The identification and analysis of minerals was performed in PPL and XPL and analysis of post-mortem specimens in UV light, also.

\section{RESULTS AND DISCUSSION}

\subsection{Aggregates - thin section analysis}

All aggregates used in the research were analyzed on thin section in transmitted light before the Mortar-Bar Method test. The examples of analyzed aggregates and their characteristic images are presented in Figures 1-4.

a)

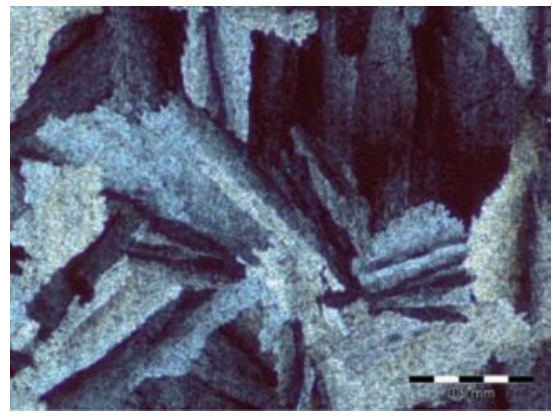

b)

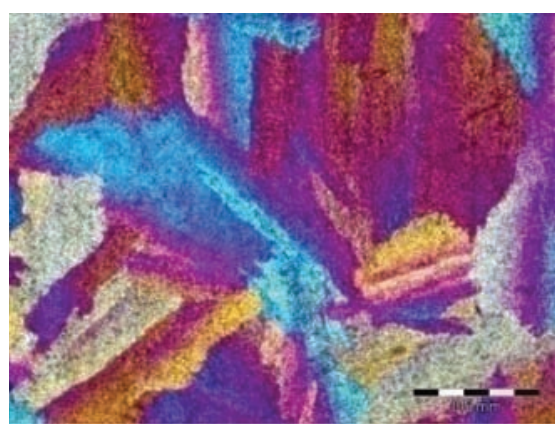

Figure 1. Characteristic part of the barite aggregate $B$ with visible plumose masses of barite crystals: (a) XPL, (b) XPL with lambda plate $($ scale bar $=500 \mu \mathrm{m})$.

a)

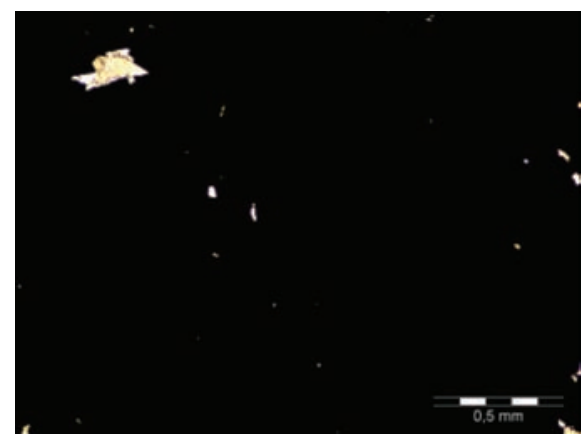

b)

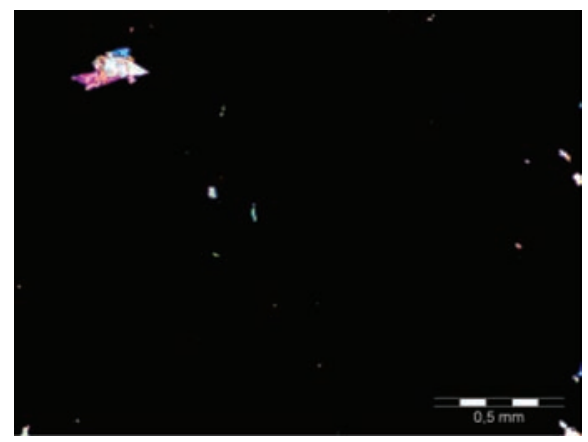

Figure 2. Characteristic part of the magnetite aggregate $M$ - opaque in thin section with colored quartz particles: (a) PPL, (b) XPL with lambda plate (scale bar $=500 \mu \mathrm{m})$. 
a)

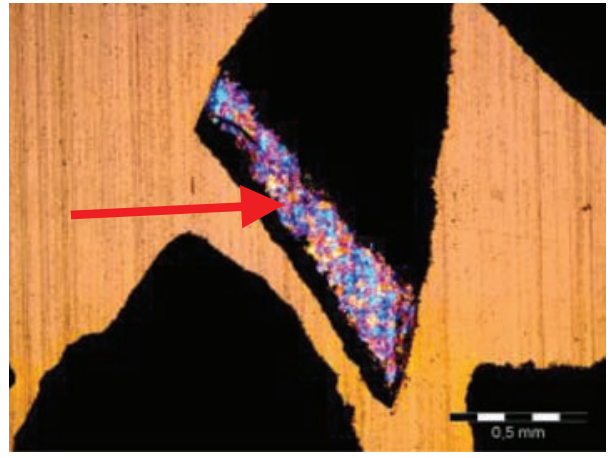

b)

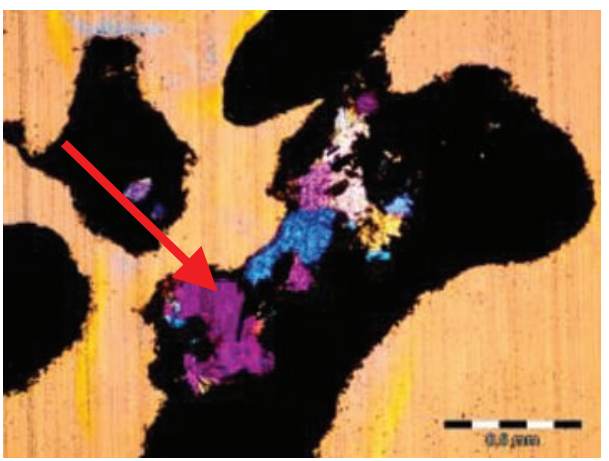

Figure 3. Characteristic part of the hematite aggregate $\mathrm{H}$ in XPL with lambda plate with visible different size of quartz crystals: (a) micro quartz, (b) macro quartz (scale bar $=500 \mu \mathrm{m}$ ).

a)

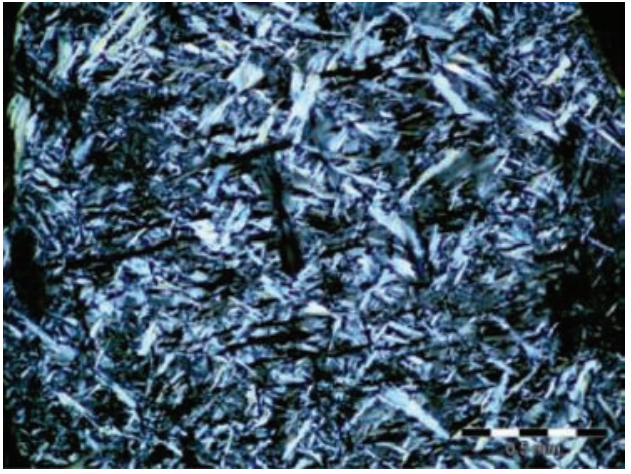

b)

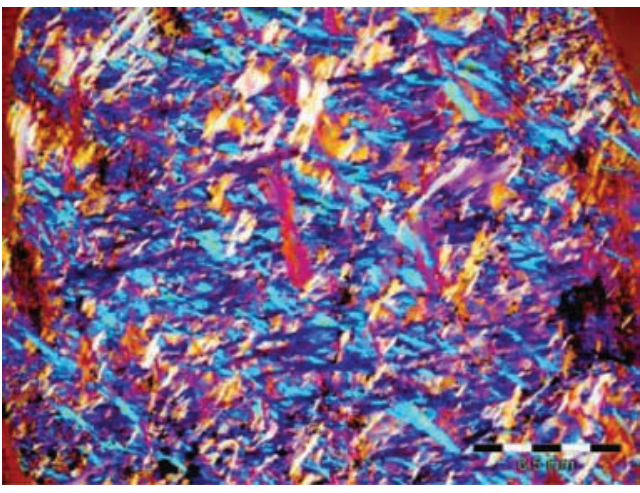

Figure 4. Characteristic part of the serpentinite aggregate $S$ with visible chrysotile fibrous crystals: (a) XPL, (b) XPL with lambda plate (scale bar $=500 \mu \mathrm{m})$.
The thin section image of radial growths of barite $B$ observed in cross polarized light shows "plumose" (like feathers) interference structure (Figure 1). Barite $\mathrm{B}$ consisted mostly of $\mathrm{BaSO}_{4}$ crystals, and only a few of $\mathrm{SiO}_{2}$ crystals were visible, which were too big (medium grained - more than $1 \mathrm{~mm}$ ) to influence the appearance of ASR. A similar situation occurred in the case of magnetite aggregate $\mathrm{M}$ - a small amount of quartz crystals, negligible with respect to ASR. The serpentinite aggregate was characterized by fibrous crystals of chrysotile (Figure 4). It also contained minor amounts of magnetite (black dots in the image).

A slightly different situation due to the risk of ASR has occurred in hematite aggregate $H$. Although most of the aggregate $\mathrm{H}$ was composed of ferrum compounds, quartz was present in the analyzed aggregates. Relatively large quartz crystals $\sim 150$ $200 \mathrm{~mm}$ (Figure 3b) do not result in ASR, as it may be in the case of smaller crystals $\mathrm{SiO} 2 \sim 20-30 \mathrm{~mm}$ (Figures $3 \mathrm{a}$ and 5 ). The size of small $\mathrm{SiO} 2$ crystals makes then a microcrystalline form of silica. Previous studies (Jóźwiak-Niedźwiedzka et al., 2015) have shown that the content of $\mathrm{SiO} 2$ in hematite aggregate was about $6 \%$. Reactivity of silica increases with decreasing crystal size so the aggregates containing microcrystalline silica should be considered potentially reactive.

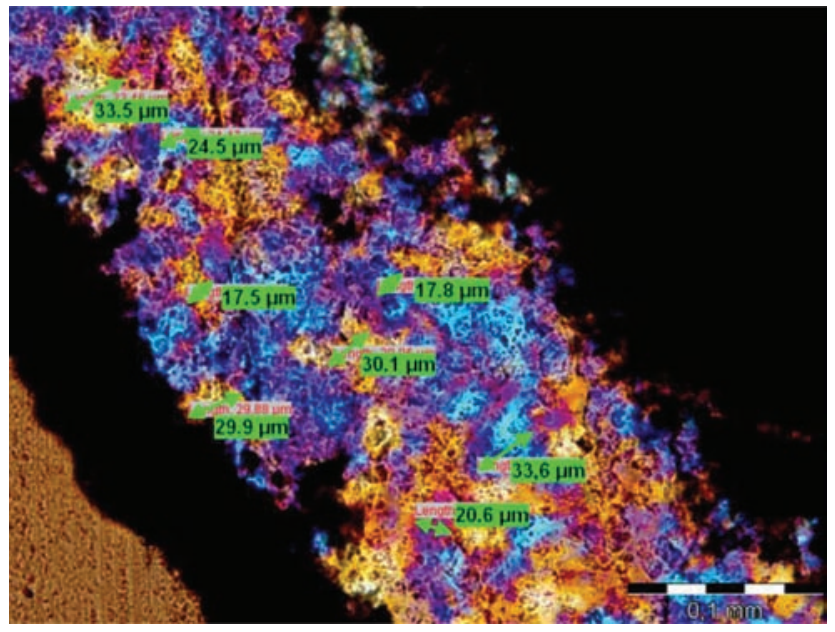

Figure 5. Part of the hematite aggregate $\mathrm{H}$ with visible size of quartz crystals: XPL with lambda plate (scale bar $=100 \mu \mathrm{m}$ ).

\subsection{Mortar-Bar test}

Results of measurement of the beams expansion as functions of their storage time in $1 \mathrm{~N}$ solution of $\mathrm{NaOH}$ in $80^{\circ} \mathrm{C}$ are shown in Figures 6 and 7. As aforementioned, the beams were prepared with four different mortars with special aggregates. Doted red line indicates maximum admissible value of linear elongation for specimens with aggregates that are 
not reactive. Expansion lower than $0.1 \%$ indicates non-reactive aggregate. Elongation between 0.1 and $0.20 \%$ shows that the aggregate is potentially reactivate, whereas elongation above $0.20 \%$ indicates very reactive aggregate.

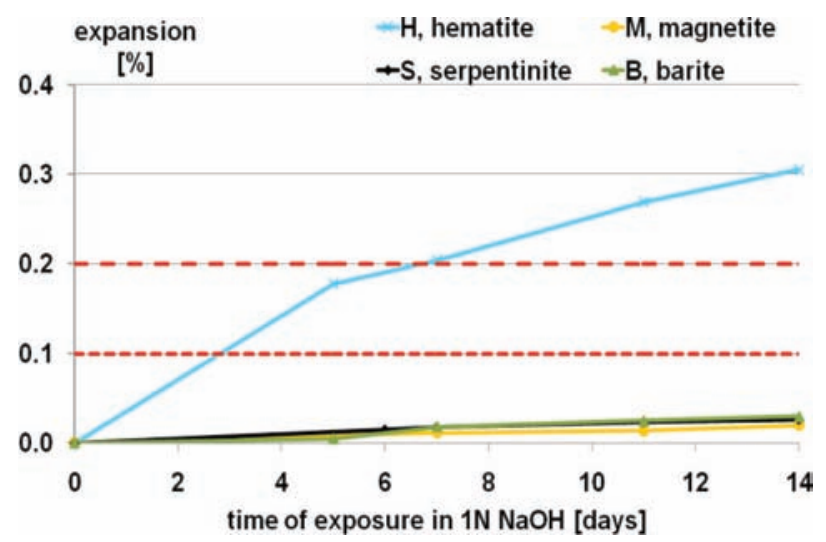

Figure 6. Expansion of mortar beams stored in $1 \mathrm{~N} \mathrm{NaOH}$ at $80^{\circ} \mathrm{C}$ during 14 days.

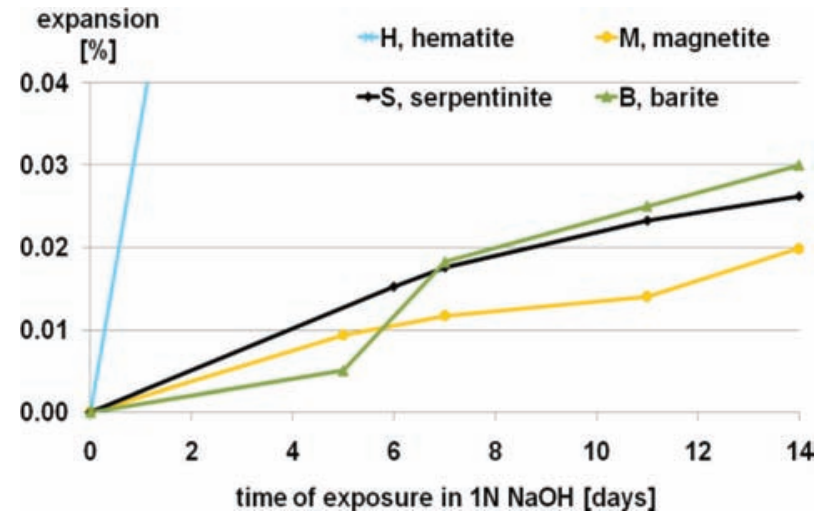

Figure 7. Expansion of examples of mortar beams - non-reactive aggregate during 14 days of exposure in $1 \mathrm{~N} \mathrm{NaOH}$.

As suspected after thin section analysis, all aggregates contained small amounts of fine- or medium-grained quartz and did not show any signs of ASR (Figures 6 and 7 ). The best results were obtained for magnetite aggregate $M$, elongation $0.02 \%$ after 14 days of testing. Slightly worse but almost similar results showed beams made with serpentinite $S$ and with barite $B$ aggregate, about $0.03 \%$. Hematite aggregate $\mathrm{H}$ showed very fast and very large beam expansion, more than $0.3 \%$, most likely due to the presence of microcrystalline silica (Figure 6).

\subsection{Mortars - thin section analysis}

After the accelerated expansion test, mortar bars were selected and the thin sections were prepared for ASR gel analysis. The evidence of alkali-silica reaction cracking and microcracking occurred in the specimens containing hematite aggregate $\mathrm{H}$ - was visible on the entire surfaces of the beams (Figure 8).

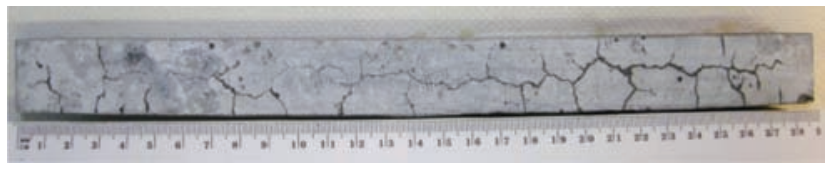

Figure 8. Characteristic map of ASR cracking on the surface of a beam with hematite aggregate after 14 days of storage in $1 \mathrm{~N} \mathrm{NaOH}$ and $80^{\circ} \mathrm{C}$.

Thin section analysis confirmed the presence of the alkali-silica gel in the hematite specimens. The gel was present both in the matrix and in the air voids. The gel due to the ASR coincided only with the grains which contained quartz. So, the hematite grains were not deleterious themselves but the microcrystalline form of quartz, which was present in the hematite aggregate.

a)

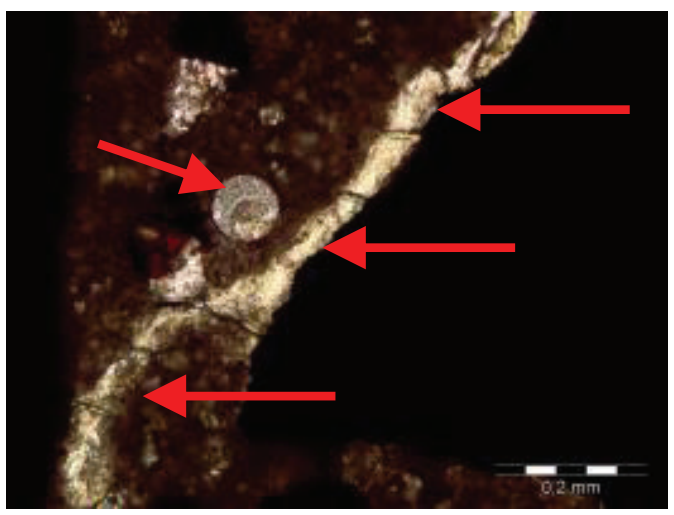

b)

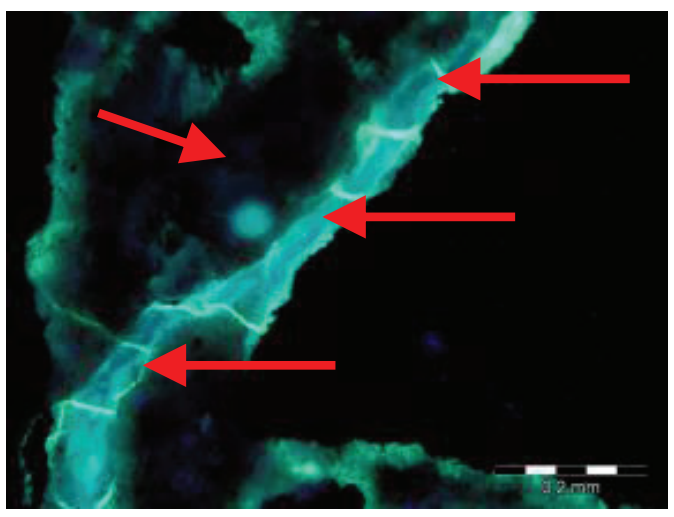

Figure 9. Cracked mortar with hematite aggregate, alkali-silica gel in the matrix and air voids: (a) PPL, (b) UV light (scale bar $=200 \mu \mathrm{m}$ ).

\section{CONCLUSION}

Thin section analysis of the aggregate was the very first step to determine the mineral composition of aggregates and detect the potentially risk of the ASR occurrence. The presence of the microcrystalline 
form of quartz has been found in one of the tested aggregates - in hematite $\mathrm{H}$. This confirmed earlier assumptions published by Swamy (1992) that it is clearly incorrect to consider rock type as a criterion for an aggregate's potential for reactivity. It is important that attention should be focused on the mineral constituents of the rock itself.

Application of accelerated method of ASTM C1260 allowed to verify whether the aggregate used in the preliminary tests is potentially reactive. The results confirmed initial worries concerning reactivity of hematite aggregates, justified by their mineralogical composition, obtained from thin section analysis.

The microstructural analysis of thin sections prepared from mortars after ASTM C1260 test confirmed the presence of ASR gel in specimens with hematite aggregate.

The experimental results give the basis to select one of checked special aggregates from among other available, which was non-reactive. Next stage of investigations leading to the design of the concrete composition for protective shields against ionising radiation will be focused on barite and magnetite as heavy aggregates and serpentinite as an aggregate with high content of bound water.

\section{ACKNOWLEDGMENTS}

The results presented in the paper have been obtained within the project "Durability and efficiency of concrete shields against ionizing radiation in nuclear power structures" (Project no. PBSII/A2/15/2014), National Centre for Research and Development.

\section{REFERENCES}

ASTM C1260. (2014). American society for testing and materials, standard test method for potential alkali reactivity of aggregates (Mortar-Bar method), annual book of ASTM standards. Philadelphia, PA: ASTM.

Ichikawa, T., \& Koizumi, H. (2002). Possibility of radiation-induced degradation of concrete by alkali-silica reaction of aggregates. Journal of Nuclear Science and Technology, 39(8), 880-884.
Jóźwiak-Niedźwiedzka, D., Brandt, A. M., Gibas, K., \& Denis, P. (2014). The alkali-aggregate reaction hazard in the case of barite concretes. Cement Wapno Beton, 19(4), 234-242.

Jóźwiak-Niedźwiedzka, D., Gibas, K., Brandt, A. M., Glinicki, M. A., Dąbrowski, M., \& Denis, P. (2015). Mineral composition of heavy aggregates for nuclear shielding concrete in relation to alkali-silica reaction. Procedia Engineering, 108, 162-169.

Jóźwiak-Niedźwiedzka, D., Glinicki, M. A., \& Dąbrowski, M. (2011). Application of microscopic techniques for studying microstructure of air-entrained concretes containing high calcium fly ash, Cement Microscopy, International Conference 33rd, Vol. 1, pp. 372-383. Red Hook, NY: Curran Associates.

Lee, S. Y., Daugherty, A. M., \& Broton, D. J. (2013). Assessing aggregates for radiation-shielding concrete, methods for petrographic examination of high-density and boron-bearing aggregates. Concrete International, 2013, 31-38.

Mather, K. (1965). U. S. Army engineer waterways experiment station (miscellanous paper No. 6-719). Vicksburg, Ml: Corps of Engineers.

Pomaro, B., Salomoni, V. A., Gramegna, F., Prete, G., \& Majorana, C. E. (2010). Effects of high energy atomic collisions and material behaviour of concrete barriers in nuclear physics experiments, XVIII GIMC Conference Siracusa, 22-24 September, 2010.

Saliba, N., Komljenovic, D., Chouinard, L., Vaillancourt, R., Chrétien, G., \& Gocevski, V. (2010). A proposed structural, risk-informed approach to the periodicity of CANDU-6 nuclear containment integrated leak rate testing Part 1, Canadian Nuclear Society, 31 ${ }^{\text {st }}$ Annual Conference, Montreal, QC, May 24-27, p. 20. doi: 10.13140/2.1.1730.4327.

Swamy, R. N. (1992). The alkali-silica reaction in concrete. Glasgow; London/New York, NY: Blackie/Van Nostrand Reinhold, p. 336.

Vonloh, J. F. (1981). Reliability growth and its applications to dormant reliability. Air Force Institute of Technology. Retrieved from Researchgate (AFIT/GOR/MA/81D-12). 